ORIGINAL ARTICLE

\title{
Presumed consent for transplantation: a dead issue after Alder Hey?
}

\author{
V English, A Sommerville
}

J Med Ethics 2003;29:147-152

See end of article for authors' affiliations ....................

Correspondence to: $\checkmark$ English, Department of Medical Ethics, British Medical Association, Tavistock Square, London WCIH 9JP, UK; venglish@bma.org.uk

Revised version received 14 February 2003 Accepted for publication 24 February 2003

\begin{abstract}
In the wake of scandals about the unauthorised retention of organs following postmortem examination, the issue of valid consent (or the lack of it) has returned to the forefront. Emphasis is put on obtaining explicit authorisation from the patient or family prior to any medical intervention, including those involving the dead. Although the controversies in the UK arose from the retention of human material for education or research rather than therapy, concern has been expressed that public mistrust could also adversely affect organ donation for transplantation. At the same time, however, the British Medical Association (BMA) continues to call for a shift to a system of presumed consent for organ transplantation. This apparent inconsistency can be justified because valid distinctions exist between the reasons requiring explicit consent for retention and the acceptability of presumed consent for transplantation. This paper argues for introducing a system of presumed consent for organ donation, given the overwhelming expressions of public support for transplantation. Ongoing legislative review in the UK provides an ideal chance to alter the default position to one where potential donors can simply acquiesce or opt out of donation. Combined with consultation with their relatives, this could be a much better method of realising individuals' wishes. It would also achieve a better balance between the duties owed to the deceased and those owed to people awaiting a transplant.
\end{abstract}

$\mathrm{P}$ atient autonomy is the centrepiece of medical ethics and so it may appear a retrograde step even to suggest that the principle of explicit consent might be superfluous in some contexts. The right to give or withhold consent, however, has generally been seen as a prerogative of the living. Until recently, generations of pathologists have assumed that different ethical standards applied to the dead. They retained samples of human material without prior authority from the deceased person or the family. In the UK, the experience of Alder Hey hospital ${ }^{1}$ changed this assumption for ever. In so far as organs or tissue are retained for education or research, the law will be amended to require the explicit prior authorisation of the donor or the family. A government consultation document exploring how this might be done was issued in mid 2002. ${ }^{2}$ How the legal and attitudinal changes envisaged for organ retention affect the availability of organs for transplantation is the subject of this paper.

Long before any discussion of organ retention, the UK always had a serious shortfall between the numbers of patients awaiting donor organs for transplantation and the available supply. Some of the reasons are self evident. Under the current UK system, potential donors need to plan for their own death and take positive steps to record their wish to donate. People do not like doing this. Donors' procrastination is often a killer for would be recipients. While repeated surveys show that more than $70 \%$ of the population claim to be willing to donate their organs for transplantation after their death, only 15\% formally join the National Health Service (NHS) Organ Donor Register. ${ }^{3}$ About $20 \%$ of the population carry an organ donor card. The apparent expectation that would be donors actively preplan and discuss their views with relatives seems ill founded. It inevitably results in the burial or cremation of organs which could have saved lives. If we believe the surveys this is contrary to what most people want. The system seems disrespectful both of the claimed altruism of most of the population and of the needs of people who, with a slight adjustment of the moral focus, could be saved. As Price points out: "the balancing of the interests of the 'giver' and 'receiver' is the great challenge for those attempting to regulate in this sphere" ${ }^{4}$ Contradictory as it seems, the present UK system appears to place more emphasis on the deceased's (assumed) lack of willingness to help than on preserving the living and, implicitly at least, raises questions about how we view the "interests" of cadavers.

\section{THE LEGACY OF ALDER HEY}

In 2000, the Bristol Royal Infirmary and Liverpool's Alder Hey Hospital were among many exposed as having retained children's organs and body parts following postmortem examinations. For the most part, the families of the deceased children were unaware of this as the law was somewhat vague about the need for relatives' permission. ${ }^{5}$ Even the medical profession did not know the scale of this practice until a census was ordered by England's Chief Medical Officer (CMO). In 2001, this exercise uncovered more than 54000 organs, body parts, stillborn children, or fetuses that had been retained since $1970{ }^{6}$ Similar findings were made in Wales, Scotland, and Northern Ireland. The first recommendation from the CMO was that the law must be amended with immediate effect "to clarify that consent must be sought from those with parental responsibility for the retention of tissue or organs from postmortems on children beyond the time necessary to establish the cause of death". ${ }^{7}$ Subsequently a far broader programme of legislative reform covering all aspects of human material, including transplantation, was proposed. ${ }^{2}$

The censuses demonstrated that "the clinical practices that led to these sad events were clearly at variance with what people felt they had a right to expect" and "a consequence has been to damage trust between families and clinicians". ${ }^{8}$ Public expectations had changed significantly since pathology practice first developed, and since the 1960s when the law was established. It seemed that the focus on autonomy that had become the norm in most other areas of medicine had never quite penetrated pathology. Information was often withheld for the best of motives, such as minimising the distress of the recently bereaved. This had been seen as more important than parents' need for information. It might be expected that the 
legacy of these events represents the end of any debate about presumed consent and that any use of cadaveric material will in future require explicit consent. Arguably, however, this is not the case. Surveys ${ }^{9}$ carried out after the publicity surrounding events at Alder Hey show continuing and increasing support for a shift to presumed consent, indicating that the public clearly perceives differences between the two procedures.

\section{DIFFERENCES BETWEEN RETENTION AND TRANSPLANTATION}

While it is true that public trust was jolted, there are fundamental differences between the Alder Hey events and organ transplantation. These make it inappropriate to extrapolate from one to the other. Firstly, most of the organs retained belonged to children. This emphasised the tragic and emotional aspects of their premature death. Parents rightly expect to be able to make decisions on behalf of their young children, both while they are alive and after their death. Some Alder Hey parents felt guilty for, in their view, having failed to protect their children in death as they would have in life. ${ }^{10}$ This reflects a broadly shared perception of parents as the natural decision makers for their children, with a continuing responsibility even after the child's death. The very fact of children predeceasing their parents seems contrary to the natural order in which parents go on having a crucial say in their child's management until adulthood. Giving them control of their deceased child's remains, therefore, partly mimics the relationship that would have naturally continued had death not intervened. (Because of this special role that parents have in relation to their children, the BMA has not suggested that presumed consent should be extended to those under 16.) The situation regarding the use of adult material is very different partly because the family's protective role is less relevant when individuals have been capable of registering their own views. We do not ask relatives to make decisions for adults and so there may seem something odd about asking them about donation of adult material, particularly if the prior views of the deceased are known. This differentiation between children and adults has been acknowledged in the public inquiries whose recommendations for parental consent were clearly perceived as specific to children rather than "the range of people who may or should be consulted in the case of adults". ${ }^{11}$

Secondly, retention had become a very clandestine practice because of the unwillingness to raise potentially distressing questions with relatives. Even medical experts lacked data about it until the censuses were conducted. Parents and the public at large were even less informed. A point that featured prominently in the report about Alder Hey was that "it was the common experience of the parents that they had been given little or no information as to what would happen to their babies and children or their organs and tissue, during and following the postmortem examination" ${ }^{12}$ Arguably, had parents been so informed and given the opportunity to object to their children's organs being retained, their reaction and that of the public would have been very different. It was the lack of knowledge, information, and explanation about what that involved that was the main cause of anger and distress. Parents spoke-for example, of feeling "deceived and cheated at the way removal and retention took place without their knowledge $e^{\prime \prime} .^{13}$ This is very different from transplantation, for which surveys show widespread public knowledge and support. Fear that individuals would be unaware of the need to opt out formally, or that some would not understand the procedures for doing so, are among the concerns frequently raised about presumed consent. ${ }^{14}$ Given that broad public awareness about donation exists, we believe that most adults would quickly become more knowledgeable during the wide publicity campaigns that would be needed to accompany the legislative change. People must, however, know what they are implicitly consenting to and so any new and potentially controversial innovations, such as face or womb transplants, which would fall outside the current scope and understanding of transplantation, should require explicit consent until research shows them to be within society's expectations.

Thirdly, transplantation can bring very obvious and radical life saving benefits whereas past tissue retention could not necessarily be shown to have been useful. Indeed, the secrecy surrounding retention heightened public suspicion of scientists that has long been reflected in popular fiction, folklore, and urban myths. The media focused on analogies with Frankenstein and demonised some pathologists, who were portrayed as tampering with the bodies of deceased children for no good purpose. The latter charge was further fuelled by evidence that very large amounts of tissue and organs had been taken but never used. Parents spoke-for example, of children's bodies being stripped of all internal tissue for which, in some cases, there was no obvious purpose. None of these problems would apply to transplantation.

\section{THE GAP BETWEEN WISHES AND REALITY}

Unfortunately, the continuing public avowals of support for transplantation after Alder Hey have not been translated into practice. The wishes that people repeatedly express when asked are not converted into action. In February 2001 the UK government held an organ donation summit and published for consultation a draft plan for the future of transplantation. ${ }^{15} \mathrm{~A}$ few weeks later UK Transplant's business plan $^{16}$ was approved and work began on a number of fronts, with significant new funding, to improve donation rates. Yet, more than a year later, the number of transplants for the first six months of 2002 had dropped by nearly $12 \%$ over the same period in $2001 .{ }^{17}$ The size of the drop was a surprise, but the fact of a drop in rates was not and continues the downward trend that has blighted transplantation over the last decade. Figures produced at the end of 1992 showed that during that year 2591 cadaveric transplants were carried out and 5124 people were on the waiting list. The equivalent figures for 2001 showed that 2339 cadaveric transplants were carried out (a decrease of $9.7 \%$ ) and that 6842 people were on the waiting list (an increase of 33.5\%). ${ }^{18}$ At 13.1, the UK's donation rate per million of the population was the lowest in Europe during 2001. ${ }^{19}$ Such statistics reflect the tragedy of real people who are dying unnecessarily but are far from the media spotlight.

The BMA has repeatedly called for much greater publicity to be given to the need for organ donation and to the true scale of the avoidable loss of life resulting from the current system. Changing the culture to one of presumed altruism requires a lead from politicians who fear the likely unpopularity of moves towards a "nanny" state. Nevertheless, they have generally felt justified in intervening in other cases when faced with data about preventable deaths. When the government reacted to the statistics of road traffic fatalities by legislating to make use of car seatbelts compulsory, for example, the initial public irritation was seen as of lesser importance than the overall societal benefit. If politicians and society seriously wish to reduce the gap between the availability of donor organs and the number of people waiting, radical action is needed rather than continuing strategies to amend and improve the current opt in system that have failed so spectacularly over the last decade.

\section{POSSIBLE SOLUTIONS}

In 1994 the King's Fund carried out a major survey of potential solutions to the transplant shortfall. It concluded that an ethical framework for presumed consent could be developed. It pointed out that although there were some ethical drawbacks, "an initiative which increases the supply of organs will, ipso facto, have one very important ethical argument in its favour: the potential to avoid death and relieve suffering". ${ }^{20}$ 
The BMA had been impressed by this report in the mid 1990s and continued to debate the issues, focusing initially on the possible option of "elective ventilation" although legal advice obtained by the Department of Health subsequently declared this option unlawful. ${ }^{21}$

In June 2000 the BMA published its own report, ${ }^{22}$ outlining a range of options for improving the organ donation system. It conceded that this was not an easy or straightforward task and that no single change would be enough, but a radical review of the whole organ donation system was needed. The donation programme had developed in a piecemeal fashion without a clear direction and the infrastructure needed a thorough overhaul. The BMA called for an increase in the use of living and non heart beating donors and, more controversially, a shift to a "soft" system of presumed consent for those over the age of 16. Under such a system, sometimes also known as "presumed consent with safeguards", organs could be used for transplantation after the death of a person over the age of 16 unless:

- that person had registered an objection during his or her lifetime;

- discussion with relatives and people close to the deceased revealed an unregistered objection; or

- to proceed would cause severe distress to those close to the deceased.

In our view there are good ethical arguments for supporting this, and it is to these that we now turn.

\section{AUTONOMY AFTER DEATH?}

For living people, the ability to control what happens to their bodies is acknowledged to be a fundamental right of all competent adults. In the UK, this principle of self determination is so highly regarded that competent adults are allowed to die rather than have life prolonging treatment imposed contrary to their wishes. Notions of providing treatment merely because it might be "in the patient's best interests" are eschewed as outdated paternalism. Patient autonomy is the key legal and ethical concept. Self determination, however, obviously requires a "self" and so it may be useful to consider briefly why society clearly considers it so important for individuals to predetermine for themselves how their remains should be handled after death.

For some people, this is linked to religious or cultural rituals. Foreknowledge of how their bodies will be handled after death provides important peace of mind during their lifetime. Similarly, for their families, knowing that they followed the appropriate rituals can be comforting. A desire to follow religious teachings does not, however, preclude organ donation and most major religions positively encourage donation. ${ }^{23}$ (Although the King's Fund report recommended that Muslims and orthodox Jews should be "presumed objectors", both faiths subsequently specifically endorsed organ donation..$^{24}$ ) Even for non-believers who have no preferences concerning burial or cremation, the psychological and spiritual dimensions of organ donation may be significant. Being extinct is one matter. Knowing that one's own flesh or organs live on in another body is different. Transplantation has been described as "a unique way to affirm and share our humanity" ${ }^{25}$ but the qualms people have about it also "typically spring from the depths to which the procedure touches, as well as shares our humanity". ${ }^{26}$ Qualms need to be addressed. Arguably, awareness of a shared societal responsibility for the sick and the positive life enhancing benefits for organ recipients should be a bigger part of that effort. On a more practical level, some people may fear that donation procedures might be implemented before they are really dead or that less effort will be made to keep them alive if their organs would be useful for younger patients. They may have a fear of their body being mutilated. Obviously, it is vital that research is done to ascertain what fears people really have, and that those are properly addressed as part of public education campaigns, regardless of which donation system operates.

For those who believe that death is the final frontier beyond which there is no form of continuing awareness or spiritual existence, there may seem to be few reasons for attempting to investigate retrospectively what the deceased might have intended. For many deceased people, few clues remain about whether they had any specific wishes. Nevertheless, the fact that an effort is made to identify such wishes reflects a deepseated notion that living people have rights to project their views into a future time when they have ceased to exist, in order to determine what is done to their remains. It is almost as if some ghost of their former autonomy is thought to remain, fuelling moral objections to proposals for bodies to become the property of the state to dispose of as it sees fit. ${ }^{27}$ It also reminds us that even largely secular societies value the concept of detecting and honouring the wishes of the deceased person.

\section{"OPT IN" VERSUS “OPT OUT"”}

Although legislation covering transplantation is usually characterised as being based on either explicit consent ("opt in") or presumed consent ("opt out"), this oversimplification fails to recognise the nuances that can radically alter the way the system operates in practice. In fact, these are merely two ends of a spectrum with strict explicit consent at one extreme and strict presumed consent at the other. With the former, organs can only be used if the donor has specifically authorised it and with the latter organs can be freely used unless the deceased has formally registered an objection. In practice very few, if any, systems operate at either end of the spectrum. Most countries operate a system that permits some degree of involvement by relatives (see below). ${ }^{28}$ Although the UK is usually presented as an "opt in" system, the current legislation ${ }^{29}$ does not require explicit consent from donor or relatives. Instead, in the absence of any statement of the individual's wishes, the hospital authority must make reasonable inquiries to ensure that no surviving relative objects before proceeding with donation. By custom and practice, however, donation is triggered either by express consent from the individual while alive or the authorisation of surviving relatives. In Belgium, which is usually held up as the model for presumed consent legislation, relatives are still consulted before organs are removed and have the option to veto the donation although they rarely do so. France and Spain also have opt out systems but again, in practice, relatives are consulted.

Clearly, the ideal situation is where individuals make a positive choice to donate tissue or organs after their death for the benefit of others. Current reality, however, is far from this paradigm. In practice the vast majority of donors have never positively consented to donation and the whole system would collapse if explicit consent were an absolute requirement. Where necessary, pragmatism rules. Against this background, the real choice for society is not between explicit consent and presumed consent. Rather it is a choice between lack of objection of the relatives and the presumed consent of the individual. Still focusing on the ghost of the individual's former autonomy, we may ask which of these options is more likely to reflect the deceased's wishes. Arguably, if it were common for families to discuss tissue and organ donation, it would clearly be the former since relatives could convey those conversations. Generally, however, this does not happen and nor have repeated publicity campaigns over many years inspired such family chats. Excluding perhaps religious sects which have a clear policy on the subject, most people are ignorant of their relatives' general views about donation or whether they have differing opinions about corneas and kidneys. For this reason when asked, relatives frequently opt for the default position, which is not to donate. In fact, many 
people whose relatives refuse on their behalf would probably have either agreed to donation or at least not held an objection.

\section{WHY IS IT REASONABLE TO PRESUME CONSENT?}

Given that most people, when asked, express willingness to donate their organs after their death, there are reasonable grounds for presuming that they probably really do wish to donate. The current law, however, presumes they do not. Statistically, it seems that the default position is more likely to be correct if it is based on the individual wishing to donate, unless there are clues to the contrary. Arguably, therefore, unless all the opinion polls are wrong, presumption in favour of donation is more likely to realise the autonomy of the deceased person than a presumption against. This only holds true, however, if individuals are aware that their organs may be used for transplantation and are given a genuine opportunity to object. Providing a simple and effective opportunity for people to opt out is crucial to a presumed consent strategy both from an ethical and legal perspective. ${ }^{30}$ It is achievable. It also seems somewhat bizarre that society assumes that most citizens are more likely to refuse than to help others, when there is no harm or benefit with either choice for the deceased. Arguably, where we have no evidence of views, "if we are to presume anything, we should presume that people would wish to do the morally right thing in the particular situation. In the case of cadaver organs this is certainly to make them available for life saving or life enhancing use ${ }^{\prime \prime}{ }^{31}$

People tend to fall into one of three categories in their views on organ donation. Some are keen to donate and they form the small minority who take active steps to record their wishes by joining the NHS Organ Donor Register, carrying a donor card and informing people close to them. There is another group who, for various reasons, definitely do not wish to donate. If genuinely adequate publicity and education is provided about registering a choice, they are not disadvantaged. Obviously, to protect the wishes of this group, everyone must be given detailed information well in advance of any change in practice and multiple, reliable opportunities to register an objection. In our view, the vast majority are those who repeatedly answer positively to surveys about organ donation but are not sufficiently motivated to take positive action now, assuming that they have plenty of time to reflect later. Arguably, the current system, which presumes objection, fails this group as well as those who would have been organ recipients under a system of presumed consent.

\section{HARM AND BENEFIT TO ALL PARTIES: THE IMPACT OF THE RELATIVES' ROLE}

Relatives provide information about the deceased person including factors that might preclude donation. Although not required by the UK legislation, in practice they are also usually asked to consent to the donation. This reflects some contradictions about how we view the rights of the living and the dead. In England, Wales, and Northern Ireland, nobody can legally consent or refuse interventions on behalf of a living adult. When patients are alive but mentally incapacitated, relatives' views provide part of the assessment of the patient's best interests but are not necessarily determinative. They have an important but limited role in helping health professionals to decide about the patient's best interests, by feeding back what the individual would have wanted. Yet, once the patient has died, the family's role changes. Rather than simply providing information about the patient's wishes, relatives are asked to make the decision on behalf of the deceased person. As already mentioned, this would be logical and consistent if relatives generally knew the deceased person's intentions but this is seldom the case. Decisions about donation generally have to be made quickly and if unsure, the temptation is for relatives to resort to the established default position and say no. This is a decision some relatives subsequently regret. ${ }^{32}$ In contrast, many other families retrospectively feel comforted by the knowledge that their loved one's organs saved or transformed other people's lives. They feel that their loss has not been devoid of all meaning and benefit.

Arguably, simply changing the default position could have huge benefits. Not least for relatives themselves who, at a time of emotional upheaval and bereavement, may not relish being asked to decide in the absence of any indication of the wishes of the deceased. One of the advantages of a presumed consent system is that the main burden of making this decision is lessened for the relatives although they would still be involved. A genuine culture change over time would mean that donation would come to be seen as the norm for most people.

One rationale for currently allowing relatives to make the decision is that they are the ones most likely to be hurt or upset if they feel the wrong action has been taken. Since they are likely to be already distressed by bereavement, it is generally felt that their wishes should be sensitively respected even if they are not necessarily in accord with those of the deceased. (Under current practice, families can overrule the deceased's donor card even though this is contrary to the spirit of the law.) The need for the living to feel comfortable about organ donation may well be a valid reason for giving precedence to relatives' wishes over other considerations, including the deceased's intentions. Clearly, there is a logic in placing greater emphasis on the needs of the living. But if society is serious about maximising benefit for living people, greater attention should be directed to the frequently overlooked needs of patients waiting for organs. The rights of this group to have their very urgent needs taken seriously in debate are often underplayed, as are the duties owed to them by society at large. While not wishing to imply that members of society have enforceable obligations to benefit one another, the BMA has previously drawn attention to ways in which the emphasis on individual rights in medical ethics sometimes overshadows any concept of responsibilities. ${ }^{33}$

Whether relatives should have the right of veto over donation has been the subject of debate since the very early years of transplantation. In parliament when the 1961 act was being debated, the health minister, Enoch Powell, argued that when evidence exists of the deceased person's wish, there should be no question of relatives having a veto. Their views, he said, were only significant in the absence of any indication of the deceased person's wishes. In that situation, he considered it right to be sure that it would not "outrage the surviving spouse or any relative if the body were so used". ${ }^{34}$ Given the emphasis, both then and now, on respecting the individual's wishes about donation, it seems entirely appropriate that the relatives should not be able to veto the express wish of the deceased and that a signed donor card or registration with the Organ Donor Register should not be overridden. Few people would oppose that principle but this is a situation where principles and pragmatism may conflict.

Currently, only a small number of relatives are known to override the documented wishes of the deceased. In exceptional cases where relatives insist that organs are not used, the benefit of proceeding needs to be balanced against the harms of ignoring the relatives' views. This harm potentially includes a number of factors, including the previously mentioned risks of distressing relatives, creating dilemmas for the health care team, and the counterproductive effect that bad publicity could have on the organ donation system as a whole. In practice, although transplant teams endorse the principle of respecting the individual's wishes, from a pragmatic perspective they cannot risk major harm to the system for the sake of very few donors. Flexible and humane solutions need to encompass the full picture in terms of benefit and harm.

The possibility of relatives refusing donation when the deceased person actually wished to donate has already been 
mentioned. The opposite can also happen. Currently, individuals who strongly object to donation lack any formal mechanism for registering that objection and the decision to donate may ultimately be made by distant relatives. Under the opt in system, there are no guarantees that relatives will not act contrary to the strongly held views of a deceased person, either through lack of knowledge or lack of agreement with them. In this way, an opt out system where objections can be registered, and must be respected, would enhance individual autonomy for those who do not want to be donors. ${ }^{35}$

\section{PRESUMED CONSENT AS A SOLUTION}

We have argued that presumed consent with safeguards is the fairest system for ensuring that an individual's wishes about donation are respected and that the needs of those with organ failure are brought more into focus. As one part of a broader reform of the organ donation system, presumed consent could significantly increase transplantation rates and the number of lives saved. Meaningful data on the success or otherwise of presumed consent regimes in other countries are, however, elusive. This is because the system of consent is only one factor that may impact upon donation rates. Other factors include:

- The predominant cause of death (such as the number of road traffic accidents);

- The availability of intensive therapy unit beds and staff;

- The number, efficiency, and enthusiasm of transplant coordinators:

- The number of transplant surgeons;

- The number of specialised units in the region, and

- The number and characteristics of the patients on the waiting list (such as what organs they need).

Comparative data between countries are difficult to interpret for this reason and it is impossible to say for certain the impact that presumed consent has on donation rates. Perhaps the most useful analysis that has been undertaken is a comparison of donation rates in Antwerp and Leuven, two centres in Belgium which have little variation in terms of these other factors and both of which were exposed to publicity surrounding the introduction of new legislation in 1986. Antwerp did not introduce the new presumed consent system initially and its donation rates remained the same. Leuven, however, adopted the new law and its rates rose from 15 to 40 donors per year over a three year period. ${ }^{36}$ It is also noteworthy that Denmark had one of highest donation rates in Europe until 1986 when its presumed consent law was changed to express consent, after which donation rates fell by a half. ${ }^{37}$ These data and a general tendency for countries with presumed consent to have higher donation rates, ${ }^{38}$ leads us to believe that provided it is accepted by the public and health professionals, presumed consent would lead to an increase in donations. It is certainly true, however, that presumed consent is not the only factor that increases donation rates, and Spain provides the clearest example of how developing the infrastructure can lead to vast improvements. Debate about whether presumed consent or developing the infrastructure is the most effective method might be an interesting academic debate, but is futile when the option of developing the infrastructure within which a presumed consent system is operated, seems to be the obvious way forward.

The perception that presumed consent will increase donation rates is not merely based on the mechanics of the system but also on the impact such a change will have on public opinion. Presumed consent represents a positive endorsement of organ donation as a good thing to do and with this formal acceptance will come a time when donation will come to be seen as the norm, rather than the exception. This compares with the existing legislation, which has been described as "a less than energetic endorsement of transplantation".$^{39}$ An understandable concern is that such a change would risk a backlash against donation. ${ }^{40}$ This concern alone, however, should not be used as an excuse for failing to consider an option that has already become standard practice in many other countries. Rather, it highlights the importance of stimulating debate and gaining public support before implementing such a change. The government needs to decide what its policy will be on donation and this is the time to initiate change, when extensive legislative reform is already on the cards and public opinion seems positively disposed to transplantation. A neutral approach, focusing solely on regulation would represent a lost opportunity. Politicians should be actively seeking to facilitate and encourage transplantation. The best way to achieve the latter is to move the debate strongly towards wider discussion of presumed consent, highlighting that this is, not only the known wish of the majority of the population but is also, the right thing to do to help those in society who are sick or dying.

\section{CONCLUSION}

Repeated calls have been made for the "opt in" system to be reversed, reflecting the fact that the majority of people claim to be willing to donate. Opinion polls amongst the public and politicians at the end of the twentieth century reported increasing support for such a change. It seemed, however, that any notion of presumed consent might have been dealt a fatal blow in early 2001 by reports of events at Alder Hey Hospital and other hospitals, where stockpiles of children's organs had been retained without the knowledge or consent of their parents. The reports and guidelines that followed stressed the need for detailed information to be provided and for explicit consent to be sought for the retention of organs following postmortem examination. ${ }^{711}$ They also fuelled calls for urgent and radical law reform about use of human material. Proposals for such reform were published in 2002 and provide new stimulus to the transplantation debate. The BMA has supported these calls, believing that a shift to presumed consent for transplantation is not only feasible in this climate but is also the right and morally appropriate thing to do.

\section{AUTHOR'S NOTE}

Although this paper reflects the policy of the British Medical Association, the views expressed are those of the authors and not necessarily those of the BMA.

\section{Authors' affiliations}

V English, A Sommerville, Department of Medical Ethics, British Medical Association, London, UK

\section{REFERENCES AND NOTES}

1 Redfern M. The Royal Liverpool Children's Inquiry Report. London: The Stationery Office, 2001

2 Department of Health \& Welsh Assembly Government. Human bodies, human choices: the law on human organs and tissue in England and Wales, a consultation report. London: Department of Health, 2002.

3 Written answer: organ donor register. House of Commons official report (Hansard) 2002 June 13, vol 1386, no 158: col 1445W.

4 Price D. Legal and ethical aspects of organ transplantation. Cambridge: Cambridge University Press, 2002: 2

5 The Human Tissue Act 1961 provided for inquiries to be made about whether the deceased or the relatives had any objection to the retention of organs and tissue but it was unclear about how rigorous such inquiries had to be and what information had to be given to relatives. There was no proper definition of what human material was covered by the act and no effective sanctions for breaching it.

6 Department of Health. Report of a census of organs and tissues retained by pathology services in England. London, The Stationery Office, 2001.

7 Department of Health, Department for Education and Employment and Home Office. The removal, retention and use of human organs and tissue from postmortem examination. London: The Stationery Office, 2001: 38. 8 See reference 2: 2

9 In July 2000, an Omnibus survey of 2000 people carried out on behalf of the National Kidney Research Fund found that $57 \%$ of those questioned would support a system of presumed consent. In February 
2001, a telephone poll conducted by the BBC's Watchdog Healthcheck attracted nearly 52000 callers of whom $78 \%$ supported a shift to presumed consent. A survey of MPs carried out in March 2001 by the National Kidney Research Fund found that $59 \%$ of the 163 MPs who completed the questionnaire supported a shift to presumed consent.

10 See reference 1: 408 .

11 The Bristol Royal Infirmary Inquiry. The inquiry into the management of care of children receiving complex heart surgery at the Bristol Royal Infirmary. Interim report. Removal and retention of human material part IV. London: Central Office of Information, 2001: 49.

12 See reference 1: 360

13 See reference 1: 400

14 New B, Solomon M, Dingwall R, et al. A question of give and take. Improving the supply of donor organs for transplantation. London: King's Fund Institute, 1994: 61.

15 Department of Health. Organ and tissue transplantation: a plan for the future-consultation document. London: Department of Health, 2001

16 UK Transplant. More transplants - new lives. Business case to the Department of Health, England and the Health Departments in Scotland Wales, and Northern Ireland 2001-2005. Bristol: UK Transplant, 2001.

17 UK Transplant. Transplant update-June 2002. Bristol: UK Transplant, 2002

18 UK Transplant. Number of cadaveric donors and transplants in the UK, 1992-2001 and patients on the active and suspended waiting lists at 31 December. Bristol: UK Transplant, 2002.

19 UK Transplant. Organ donation and transplant activity per million population (pmp) in Europe, 2001. Bristol: UK Transplant, 2002.

20 See reference 14: 61

21 NHS Executive. Identification of potential donors of organs for transplantation. 1994 Oct 10: HSG(94)41.

22 British Medical Association. Organ donation in the 21 st century. Time for a consolidated approach. London: British Medical Association, 2000.

23 National Museum of Photography, Film and Television, Bradford.

Conference proceedings: organ donation \& transplantation-the multifaith perspective. Bradford: The Bradford Hospitals NHS Trust, 2001

24 See reference 23: 13 and 17.

25 Youngner S. Psychosocial and ethical implications of organ retrieval. N Engl J Med 1985;313:321-4 at 323.
26 See reference $4: 1$

27 Harris J. Clones, genes and immortality. Oxford: Oxford University Press, 1998: ch 5 .

28 For a good discussion of different laws on organ donation see reference 4.

29 Human Tissue Act 1961 for England, Scotland, and Wales and Human Tissue Act (Northern Ireland) 1962 for Northern Ireland.

30 Provided individuals have a genuine opportunity to opt out of donation, it is difficult to envisage any breach of people's legal rights including those conferred by the Human Rights Act.

31 Erin CA, Harris J. Presumed consent or contracting out. J Med Ethics 1999:25:365-6.

32 Two studies undertaken in Spain found that 30\% of families that refused consent would have changed their minds one year later. These studies were quoted in: Council of Europe. Meeting the organ shortage. Current status and strategies for improvement of organ donation. Strasbourg: Council of Europe, 1999.

33 British Medical Association. Human genetics: choice and responsibility Oxford: Oxford University Press, 1998: 11-26.

34 From our parliamentary correspondent. Approval for Human Tissues Bill. BM 1961;1:61.

35 Somerville MA. "Procurement" $v$ "Donation"-access to tissues and organs for transplantation: should "contracting out" legislation be adopted? Transplantation Proceedings 1995; XV11 (suppl 4):53-68S.

36 Kennedy I, Sells RA, Daar AS, et al. The case for "presumed consent" in organ donation. Lancet 1998;351:1650-2.

37 This drop was also undoubtedly due in part to debate about the definition of death. See Rix B. Brain death, ethics, and politics in Denmark. In: Youngner SJ, Arnold RM, Schapiro R, eds. The definition of death. Contemporary controversies. Baltimore: Johns Hopkins University Press, 1999:227-38.

38 Michielsen P. Informed or presumed consent legislative models. In: Chapman JR, Deierhoi M, Wight C, eds. Organ and tissue donation for transplantation. London: Arnold, 1997: 344-60.

39 Kennedy I. The donation and transplantation of kidneys: should the law be changed? J Med Ethics 1979;5:13-21.

40 See reference $14: 62$.

\section{eCurrent Controversies}

The JME eCurrent Controversy section pre-publishes highly topical articles that will appear in forthcoming issues of JME. This Free Access section can be viewed via the JME homepage www.jmedethics.com.

Current articles

- Bioterrorism and smallpox planning: information and voluntary vaccination. M J Selgelid

- Compulsory brain scans and genetic tests for boxers-or should boxing be banned? M Spriggs; "Boxing is Like..." C D Herrera

- Confidentiality and the ethics of medical ethics. W A Rogers, H Draper

- Cell phoney: human cloning after Quintavalle. D Morgan, M Ford; Misconceived conceptions. M Ford, D Morgan; Assisted reproductive technological blunders. John Harris

- The ethics of research related to healthcare in developing countries. J R McMillan, C Conlon

- Extending preimplantation genetic diagnosis: medical and nonmedical uses. J Robertson; Commentary on Robertson: extending preimplantation genetic diagnosis: medical and nonmedical uses. R Ashcroft

- Should HIV discordant couples have access to assisted reproductive technologies? M Spriggs, T Charles

- Woman wants dead fiancé's baby: who owns a dead man's sperm? M Spriggs

- Therapeutic cloning research and ethical oversight. M Spriggs

- Commodification of children again and non-disclosure preimplantation genetic diagnosis for Huntington's disease. M Spriggs

- MRSA in The Netherlands. Preventive measure raises a moral issue. D O E Gebhardt 